\title{
A educação fora da escola: a mercantilização e a disciplina do lazer nas Colônias de Férias
}

\section{Education out of school: the commodification and discipline of leisure in the Holiday Colonies}

\author{
Stephany de Sá Nascimento* \\ Rafael da Silva Mattos*
}

\begin{abstract}
RESUMO
O objetivo desse estudo foi discutir a mercantilização do lazer nas Colônias de Férias. Trata-se de um trabalho qualitativo com uso de entrevistas semiestruturadas com 10 profissionais de Educação Física que atuaram em diferentes Colônias de Férias do município do Rio de Janeiro. Para a análise dos resultados foi empregada a técnica de Análise do Conteúdo segundo Laurence Bardin. Constatou-se que a Colônia de Férias é mais uma forma de lazer na figura de mercadoria. Isso atrai o uso de técnicas disciplinares por parte dos professores para que estes consigam administrar, por exemplo, grandes quantidades de alunos que ficam sob sua responsabilidade. Este fato é semelhante ao que acontece no ambiente escolar. Concluiu-se que as práticas disciplinares e a violência entre os alunos também estão na lógica de funcionamento das Colônias de Férias, o que pode dificultar o lazer como prática de emancipação, diversão e liberdade.
\end{abstract}

Palavras-chave: Criança. Educação extraescolar. Férias. Atividades de lazer.

\begin{abstract}
This study aimed at discussing the leisure commodification in summer camps. This is a qualitative work that used semi-structured interviews
\end{abstract}

* Universidade do Estado do Rio de Janeiro. Rio de Janeiro, Rio de Janeiro, Brasil. E-mail: nascimento_stephany@hotmail.com - https://orcid.org/0000-0002-0206-9787 E-mail: profmattos2010@gmail.com - https://orcid.org/0000-0002-1314-050X 
with 10 Physical Education professionals who worked in different summer camps in the city of Rio de Janeiro. Content Analysis by Bardin was used for analyzing the results. It was found that the summer camps are another form of leisure in the figure of merchandise. Disciplinary techniques are used by professors to manage many students under their responsibility, for example. This fact is similar to what happens in the school environment. The conclusion points out that disciplinary practices and violence among students are also part of the working logic in summer camps, what might difficult the leisure as emancipation, amusement and freedom practices.

Keywords: Child. Outside school education. Vacation. Leisure activities.

\section{Introdução}

As Colônias de Férias são eventos bem difundidos no Brasil. Por conta das características de suas atividades, vários professores de Educação Física estão envolvidos e trabalhando nestes espaços. As principais atividades da maioria das Colônias de Férias são físicas, como: jogos, modalidades esportivas, atividades recreativas, rítmicas, entre outras. Isso porque a finalidade geralmente é proporcionar aos escolares em férias a oportunidade de preencherem esse período de forma orientada com atividades físicas e de lazer, estimulando o gosto por elas, despertando espírito de equipe, ação comunitária, autonomia, liderança e espírito esportivo (SILVA, 2008; MARCELLINO, 2000).

A origem das Colônias de Férias foi motivada a partir de duas perspectivas: a pedagógica e a higiênico-sanitária. A primeira delas diz respeito à necessidade de amenizar os impactos gerados pelo excesso de intelectualismo escolar e os hábitos sedentários transmitidos na escola. Já a perspectiva higiênico-sanitária fundamentou-se, pois, algumas classes eram submetidas a condições precárias de moradia o que contribuía para uma alta taxa de mortalidade infantil. As Colônias de Férias eram vistas como um paliativo para esta situação já que mantinham as crianças longe destas condições pelo menos por um tempo (MARTÍNEZ, 2009).

Segundo Berto, Ferreira Neto e Schneider (2009), as Colônias de Férias das décadas de 1930 e 1940 no Brasil eram consideradas instituições extraescolares e eram tidas como um plano para o futuro da nação, uma forma de apresentar noções de saúde e higiene para os participantes. A finalidade também era desenvolver as crianças para que fossem civilizadas e prontas para o progresso, cidadãos do amanhã. Os principais propósitos eram de regeneração, civilização e nacionalização a partir da disciplina. 
Ainda hoje podemos afirmar que há uma forte presença do poder disciplinar e da biopolítica nas Colônias de Férias que são uma herança das características que deram origem e que perpetuaram esses eventos durante os últimos anos (MATTOS et al., 2017). Atualmente as Colônias de Férias ocupam um lugar de "produto" a ser consumido durante as férias. Silva (2008) chama atenção para o "pacote de atividades" que geralmente é imposto às crianças por conta do interesse do mercado. Esta formatação desconsidera as características que são específicas de cada grupo, além de reduzir as possibilidades de desenvolvimento que o lazer oportuniza.

Segundo Viana (2015), a mercantilização do lazer é inseparável de sua burocratização e de seu controle. Isso significa que "[...] se os indivíduos já se encontravam controlados em seu trabalho, para-trabalho e obrigações sociais, agora mais um momento de sua vida passa a sofrer um controle externo" (VIANA, 2015, p. 66). O que nos faz inferir que além do ambiente escolar, aqueles voltados para a educação informal seguem pelo mesmo caminho da maioria dos modelos pedagógicos já existentes. Modelos estes que continuam formando alunos passivos e receptores, pois eles não são os formuladores de questões e sim aqueles que sempre recebem ordens e tarefas (CRUZ, 2011; FREITAS, 2015).

As Colônias de Férias estão agindo da mesma maneira que a pedagogia tradicional contribuindo para que os indivíduos fiquem mais apáticos até mesmo em raros momentos em que poderiam ser protagonistas de sua vida e formação. Uma Colônia de Férias poderia ser uma grande ferramenta para a construção coletiva, mas para isso é preciso superar certas práticas de caráter ocupacional e assistencialista e pensar em maneiras críticas e criativas que possam estimular a autonomia das crianças. Silva (2008, p. 18) explica:

Ao mesmo tempo em que as Colônias de Férias se configuram um campo de atuação profissional de número significativo, senão predominante, de Educadores Físicos, ainda são propostas pouco sistematizadas, o que acarreta a escassa produção sobre a temática, sugerindo uma ação pouco refletida.

Sendo assim, o presente trabalho objetivou compreender a mercantilização e a disciplina do lazer presentes nas Colônias de Férias. Pode-se dizer que este estudo considerou a sugestão de Mattos et al. (2017), contribuindo para a ênfase na apresentação de resultados empíricos mais recentes, uma vez que a área do lazer carece deste tipo de conteúdo. 


\section{Método}

O presente estudo é de caráter qualitativo uma vez que ele buscou compreender os sentidos de uma experiência dentro de uma esfera específica dos participantes. Utilizamos como recurso a análise do conteúdo (BARDIN, 2011, p. 48), definida como:

um conjunto de técnicas de análise das comunicações, visando obter, por procedimentos sistemáticos e objetivos de descrição do conteúdo das mensagens, indicadores [...] que permitam a inferência de conhecimentos relativos às condições de produção/recepção [...] dessas mensagens.

Para atender ao objetivo proposto, estabelecemos como sujeitos da pesquisa $10(\mathrm{dez})$ Professores de Educação Física que atuaram ou atuam como Professores e/ou Coordenadores de diferentes Colônias de Férias do Município do Rio de Janeiro. A escolha dos profissionais e das Instituições que eles trabalham foi feita por conveniência, obedecendo ao critério de inclusão de ter trabalhado em pelo menos duas Colônias de Férias como Professor e/ou como Coordenador nos últimos 5 anos. Este critério assegurou que os informantes tiveram mais de uma experiência ${ }^{1}$ profissional em Colônias de Férias, o que pode aumentar a credibilidade das narrativas recolhidas.

Os dados foram coletados no primeiro semestre de 2016 através de entrevistas semiestruturadas. O uso da entrevista semiestruturada se apoiou na possibilidade de nortear as questões que o entrevistador julga como importantes para o objetivo de seu estudo, ao mesmo tempo em que liberdade da interação com o entrevistado é garantida (AMADO, 2017).

Seguindo a metodologia da análise categorial, estabelecemos como unidade de registro o tema, buscando nessas comunicações os núcleos de sentido aparentes, que proporcionam entendimento sobre o assunto estudado. Para facilitar a compreensão dos procedimentos relativos à análise do conteúdo, seguindo a recomendação de Bardin (2011), dividimos as ações em três etapas. Inicialmente, realizamos uma pré-análise através da leitura flutuante, captando

1 Compreendida segundo Bondia (2002, p.21): “A experiência é o que nos passa, o que nos acontece, o que nos toca. Não o que se passa, não o que acontece, ou o que toca. A cada dia se passam muitas coisas, porém, ao mesmo tempo, quase nada nos acontece." 
o conteúdo sem, contudo, ater-se pormenorizadamente às técnicas de apreensão. Posteriormente, procedemos com a exploração do material de forma mais aprofundada, elaborando os indicadores, recortes do texto e categorização. Por fim, realizamos as interpretações dos dados. Aprovado pelo Comitê de Ética em Pesquisa sob o número CAAE: 50712915.9.0000.5259.

\section{Resultado e discussão}

O Quadro 1 apresenta os indicadores e as categorias que emergiram da análise do material coletado nas entrevistas. A categorização aponta uma forma de ordenação da realidade pesquisada no intuito de compreendê-la de maneira global.

QUADRO 1 - INDICADORES E CATEGORIAS QUE EMERGIRAM DA ANÁLISE DAS ENTREVISTAS

\begin{tabular}{|c|c|c|}
\hline Categorias & $\begin{array}{c}\text { Mercantilização do Lazer nas } \\
\text { Colônias de Férias }\end{array}$ & $\begin{array}{c}\text { Disciplina e o lazer das } \\
\text { Colônias de Férias }\end{array}$ \\
\hline Indicadores & $\begin{array}{c}\text { Quantidade de alunos x qualidade do } \\
\text { serviço prestado/Produção }\end{array}$ & $\begin{array}{c}\text { Necessidade dos pais/Colônia de Férias } \\
\text { como uma escola/ Valores sociais } \\
\text { Violência }\end{array}$ \\
\hline
\end{tabular}

FONTE: Elaborado pelos autores, 2019.

\section{A mercantilização do lazer nas Colônias de Férias}

Os entrevistados demonstraram descontentamento com os preceitos que as Colônias de Férias carregam. Encontraram-se informações claras de que estes espaços deveriam ter a intenção voltada para o lazer de crianças e jovens. No entanto, alguns professores lamentam a entrega destes espaços para intenções consideradas comerciais.

Na verdade, as Colonias de Férias seriam um grande momento de lazer e de vivências para elas, hoje em dia, infelizmente, está muito 
mercantilizado. Muito mais a questão de quantidade de alunos do que qualidade do que você faz (Entrevistado 1).

Para o Entrevistado 1, as Colônias de Férias são entendidas no âmbito do mercado, pois a finalidade é possuir o maior número de crianças possível, não prezando pela qualidade do serviço. Ao introduzir o conceito de Fetichismo de Mercadoria, Marx (2013) explica que o modelo de produção capitalista, ao encobrir as características sociais do trabalho por considerá-las materiais e propriedades sociais inerentes aos produtos de trabalho, tornam-se mercadorias, coisas sociais. $\mathrm{O}$ fetichismo ocorre quando os produtos do trabalho são gerados como mercadorias.

A mercadoria é uma coisa que, a partir de seus predicados, satisfaz necessidades humanas de qualquer espécie. A mercadoria não pode ser entendida como algo simples, movida pelo consumo e produção, mas como uma detentora de mediações e determinações maliciosas (MARX, 2013).

Para Lukács (1974), a especificidade do capitalismo é a racionalidade aplicada à subjetividade e não apenas à produção. Ou seja, o fetichismo da mercadoria se espalha por todas as esferas da vida cotidiana. Bourdieu (1979, 1993) discutiu esse espalhamento da lógica do capital nas diversas áreas, como as artes, a moda, o esporte, entre outros. Com a ideia de campo ${ }^{2}$ e de mercado, o autor infere esse ajuste para o esporte moderno que, para ele, encontra-se orientado por uma lógica mercantil.

De acordo com o pensamento de Marx e com o discurso do Entrevistado 1, as Colônias de Férias assumem um caráter mercadológico. Desse modo, o que os profissionais de Educação Física produzem nas Colônias de Férias são mercadorias que dependem cada vez mais do quantitativo de crianças/clientes.

Marx (2013) afirma que, no capitalismo, não é o trabalhador que utiliza os instrumentos de produção, mas o contrário, estes instrumentos são convertidos em capital para, aí sim, utilizarem o trabalhador. $\mathrm{O}$ autor afirma que, na fábrica, o trabalhador se subordina aos movimentos da máquina obedecendo a uma finalidade, ou seja, visando o lucro. Podemos ver que a intenção dos gestores e empresários é puramente vender a mercadoria que, neste caso, é o lazer. Em

2 Para Bourdieu (2005, p. 30), um campo é um campo de forças dentro do qual os agentes ocupam posições que, estatisticamente, determinam as posições que eles tomam com relação ao campo, sendo estas tomadas de posição destinadas à conservação ou à transformação da estrutura de forças constitutivas do campo. 
outro trecho do relato do Entrevistado 6, encontramos aspectos que se ajustam à essa ideia.

[...] Já começando pela coordenação, que já não aceitava algumas práticas que eu gostaria de fazer (Entrevistado 6).

Referindo-se à relação da equipe de uma Colônia de Férias que havia trabalhado, o professor afirmou que deveria acompanhar o movimento dos gestores, fazer a maioria das atividades de acordo com a instituição proponente e obedecer às ordens para que o trabalho fosse cada vez mais uniforme e promovesse mais retorno. Isso nos faz pensar que a produção é de fato um pilar que preocupa responsáveis por este tipo de espaço de lazer. Fuchs (2017) afirma que a criação dos diplomas de animador e diretor de Colônias de Férias, na década de 1940, deu mais impulso às Colônias de Férias.

Quando um indivíduo utiliza alguns momentos do seu dia para ter instantes de lazer e os troca pelo equivalente em dinheiro, seja em um cinema, em uma exposição de artes ou em uma Colônia de Férias, ele não está trocando a objetivação do trabalho dos artistas ou dos profissionais envolvidos com a Colônia. Nem está trocando pelas horas de trabalho humano. O homem, para realizar a necessidade de consumo, submete-se a um esquema de relações de mercadorias expresso na relação pura com o dinheiro e não como resultado de trabalhos sociais e individuais.

Este mesmo processo ocorre na área da saúde e sua principal consequência é o enfraquecimento da cidadania a partir do momento em que fere o direito à saúde (SANTOS, 2013). Paulino, Siqueira e Figueiredo (2017), por exemplo, encontraram o discurso disciplinador em uma caderneta dedicada à saúde dos idosos. Eles explicam que a consequência disso é a disseminação da culpa e da responsabilização dos idosos por suas mazelas, mascarando a infraestrutura que deveria ser garantida por direito. $O$ cidadão não vê a saúde como um direito, mas como uma mercadoria. Podemos ver que este fato atinge também as Colônias de Férias, ferindo não só o direito à saúde, mas também o lazer, outro direito fundamental, segundo a Constituição.

Conforme Mendes et al. (2017), observa-se o ataque aos direitos sociais e a imposição de riscos à construção da saúde universal. Para os autores, isso não acontece apenas através, por exemplo, dos cortes nos gastos públicos veiculados à saúde, mas a partir do momento em que uma prática de proteção social é organizada de modo a servir os interesses do mercado. Com o lazer não é diferente, principalmente quando o pensamos como uma ocupação não 
obrigatória, de livre escolha que se desenvolve em um tempo que não é utilizado para as obrigações da vida, ou seja, no tempo livre (REQUIXA, 1980; LEMA; RUIZ; SCARLATO, 2011).

Essa discussão se torna ainda mais importante quando, apesar de reconhecermos a variedade dos conceitos de lazer e suas relações um pouco ambíguas presentes na literatura, consideramos a linha norteadora que entende o lazer como um conjunto de ocupações que o indivíduo pode entregar-se de livre vontade, sendo elas para repouso, divertimento, entretenimento e até para desenvolver sua informação ou formação desinteressada, ou sua livre capacidade criadora após livrar-se das obrigações profissionais, familiares e sociais (DUMAZEDIER, 1979).

A atividade laboral é o elemento que demarca a estruturação dos quadros temporais da sociedade. $\mathrm{O}$ tempo social apresenta algumas características, dentre elas está o tempo livre, que se refere às ações humanas realizadas sem que ocorra uma necessidade externa. Ou seja, o sujeito é livre para utilizar esse tempo com total autonomia e de maneira criativa, dependendo de sua consciência de valor sobre seu tempo (MUNNÉ, 1980).

Para o capitalismo o tempo livre é um desperdício, visto que o capitalismo luta cada vez mais pela ampliação de lucros. Desta forma, o tempo livre é transformado em mais uma oportunidade de ganhos e o lazer é um exemplo disso. O lazer é transformado em consumo, em lucro, considerado como um dos negócios mais oportunos e rentáveis da atualidade. A dimensão cultural do lazer é substituída completamente pela função comercial e, em paralelo ao trabalho, surgem atividades ligadas ao tempo livre. No entanto, essas atividades assumiram a forma da sociedade industrial (PADILHA, 2000).

Assim, sendo o valor de uso, a mercadoria se apresenta como uma vontade independente dos indivíduos. No caso das Colônias de Férias, os pais pagam por um suposto lazer que as crianças terão direito durante determinado período. Para Silva (2012), a palavra lazer está cada vez mais presente no cotidiano das pessoas. Todavia, isso não significa que seja vivenciado na mesma proporção. "Em geral, o lazer tem ganhado evidência por ser tratado como mercadoria, agregando valor a outros produtos [...], ou pelas suas propostas de divertimento e entretenimento a ser consumido" (SILVA, 2012, p. 12). Para a autora, isso se torna grave, pois, o uso do lazer como desenvolvimento social e pessoal acaba sendo desconsiderado.

Mascarenhas (2005) discute a dificuldade em identificar de maneira segura e decidida alguma forma de lazer que não tenha resistido à figura de mercadoria. O autor utiliza a palavra "mercolazer" para expressar a dinâmica de mercantilização do lazer em sua manifestação mais imediata, que assume a figura de mercadoria. Esta palavra também configura o lazer quando o 
[...] valor de uso prometido, quando seu poder imagético, como coisa significante, aparece involucralmente colado ao corpo de outras mercadorias; como palco de vivências, servindo de atrativo divertido e emprestando o estatuto do lazer a um conjunto de pontos de venda ou equipamentos de comércio; e como compra divertida, quando o próprio processo de troca assume a identidade de uma atividade de lazer (MASCARENHAS, 2005, p. 157).

O "mercolazer" é aceito como paradigma exclusivo para a interpretação e organização do lazer à medida que as pessoas adotam o valor e as relações mercantis como princípio orientador e organizador da vida. Considerando que o mercado é um lugar comum das práticas de lazer e que a indústria cultural se encarrega de dizer qual lazer é o melhor, parece que não há mais alternativas a não ser o próprio "mercolazer" (MASCARENHAS, 2005).

Para Camargo (2017), quase metade do tempo livre da população brasileira é gasta com o lazer produzido pela indústria cultural, o que envolve a televisão, os jornais, revistas e outros. No entanto, esses meios de comunicação de massa não passam da reprodução de conteúdos de outras práticas de lazer. Isso vale para artes, esportes e música, por exemplo. O que efetivamente esse fenômeno representa é o fato de que há certo consumo de lazer e não da prática efetiva dele.

Fuggle (2016) afirma que as Colônias de Férias foram captadas pela indústria do lazer. O discurso da liberdade e do lazer nas férias omite a ideia de produtividade no período não-escolar. A liberdade difundida é um projeto neoliberal de capturar o lazer e aumentar o controle dos recursos humanos. Tratase de uma biopolítica e até mesmo de uma vida nua (DIKEN; LAUSTSEN, 2005).

É possível pensar, a partir dos relatos recolhidos, que nas Colônias de Férias esse fenômeno se mantém de maneira diferente. O que acontece é o consumo de um lazer que é imposto, que é tido como o correto a ser praticado, inibindo a construção e a autonomia naquele tempo.

A noção de indústria cultural é atrelada à ideia de um processo de controle e organização de uma nova maneira de comunicação, que, em princípio, é vista a partir de uma tendência para a liberdade. Liberdade esta que é divulgada ao indivíduo, dando a ele a opção do que assistir, do que fazer, mediante a fartura de opções. Só que é importante lembrar que a indústria cultural consiste em moldar a produção artística e cultural. Assim, estas manifestações são vistas como mercadorias e transformadas em coisas, legitimando a alienação de uma arte que é produzida para indivíduos carentes de uma visão mais crítica. O objetivo desta indústria é criar, reforçar e manter uma nova necessidade de consumo que visa gerar suas próprias mercadorias, incentivando produtos e não o conhecimento (ADORNO; HORKHEIMER, 1990). 
A indústria produz cultura transformando-a em mercadoria com a finalidade de produzir lucro. Isso faz com que a cultura não possa existir simplesmente, ela precisa de uma finalidade para existir, reduzindo assim, sua capacidade de expressão. A cultura necessita estar submetida à lógica capitalista, gerando um efeito poderoso do capitalismo no inconsciente. Quando a cultura vira mercadoria, a lógica capitalista começa a dominar não só a alimentação, as roupas, o lazer e outros, mas também o inconsciente. Percebemos, assim, que a mercantilização do lazer e sua burocratização faz com que os indivíduos fiquem cada vez mais controlados (VIANA, 2015).

Segundo Dumazedier (1979), nem tudo que está além do trabalho é necessariamente tempo livre e não poderia então ser chamado de lazer. Algumas atividades, como cursos e outras exigências de formação e qualificação, por exemplo, são conhecidas pelo autor como atividades "para-trabalho" que são aquelas que dão suporte às obrigações sociais.

Adorno e Horkheimer (1991) afirmam que o lazer é procurado por quem tem a intenção de escapar do processo de mecanização presente no trabalho e na maioria das atividades. Porém, a mecanização tem um poder enorme sobre o lazer e a felicidade humana, este poder determina a produção de mercadorias que são destinadas à diversão, ao entretenimento, ao lazer. Ou seja, o indivíduo busca refúgio no lazer, só que a estrutura do lazer tem base na mesma lógica mecanizada do trabalho.

\section{A disciplina e o lazer das Colônias de Férias}

Alguns entrevistados demonstraram que sentem que algumas crianças não gostariam de estar ali, mas que não possuem outra opção, torcendo para que aquele momento acabe logo. Isto é uma realidade que coaduna com a argumentação acima, em que um momento que poderia ser diferente do cotidiano, se torna igual. No caso das Colônias de Férias, as crianças a veem como a escola, pois precisam frequentar sem alternativa, realizar as atividades propostas sem oportunidade de escolha, ter horários e tarefas a cumprir.

A maioria das crianças nem quer estar nas Colônias de Férias. Infelizmente, o que eu reparei é que os pais trabalham ali em época de férias letivas. Eles precisam deixar os filhos com alguém. A Colônia de Férias é a solução. Alguns sim, querem praticar, querem ir pra Colônia 
de Férias, querem jogar bola, querem piscina, mas muitas crianças não queriam estar ali. Eles sabiam "que eu tenho que ficar aqui até certo horário e daqui a pouco meus pais vem me buscar. Só quero que acabe o mais rápido possível" (Entrevistado 1).

Em consonância com este relato, Silva (2012) aponta que as Colônias de Férias são comuns no período de férias escolares, atendendo normalmente à necessidade dos pais que não possuem um local para deixar os filhos nesta época. É importante considerar que a mercantilização do lazer, a indústria cultural, e outros argumentos acima expostos, também possuem ligação com esta característica das Colônias de Férias. O que mais nos interessa aqui é como a influência do mercado atinge os profissionais e as crianças envolvidas.

Ressaltamos dois pontos relacionados ao relato abaixo. O primeiro diz respeito à criança associar a escola com a Colônia e o segundo refere-se ao comportamento da criança por identificar aquele lugar com a escola. Ela reproduz o que faz na escola, por encontrar semelhanças entre as situações.

Na verdade, ela acha que está em uma escola, em uma escola de férias e acaba repetindo o que ela faz lá (Entrevistado 7).

[...] na escola a criança já fica condicionada à punição. [...] Mas, a partir do momento que o professor mantém sua postura e explique as regras, fica simples lidar com qualquer tipo de violência, tanto na Colônia de Férias, quanto na escola. [...] Eles agridem ou fazem qualquer tipo de violência porque eles querem (Entrevistado 9).

Talvez na escola você tenha uma variedade maior de punições, mas eu acho que atitude deve ser a mesma no sentido de conversar, de orientar, de chamar a atenção (Entrevistado 6).

Segundo Antunes e Zuin (2008), ao caminhar na mesma direção dos imperativos culturais e reforçando a educação na forma de adestramento, evidencia-se a típica hegemonia da sociedade esclarecida que, ao invés de possibilitar a autonomia, conserva o padrão autoritário da cultura. Houssaye (1998) também destaca que as Colônias de Férias e demais atividades de lazer foram dominadas pela estrutura escolar. O modelo disciplinar da escola é replicado nesses locais. 
Podemos dizer que, além de ser influenciada pela escola, atualmente a Colônia de Férias recebe forte influência do comportamento do mercado, transformando-a em uma mercadoria para produzir lucro. Este processo ocorre com todas as áreas da vida, uma vez que a lógica capitalista invade o inconsciente. A visão de qualquer área do lazer como mercadoria carrega consigo uma boa dose de burocracia e de controle, fazendo com que o indivíduo fique exposto à mesma dinâmica de dominação do trabalho.

Ou seja, o indivíduo busca o lazer para livra-se, pelo menos por um momento, do processo de mecanização que o domina durante todo o dia. No entanto, o lazer segue a mesma lógica de mecanização que o trabalho. Assim,

A lógica da mercadoria e da racionalidade instrumental invade o consumo, as atividades de lazer, a arte e a cultura, de modo que a recepção cultural é condicionada pelo valor de troca, na mesma medida em que os valores e propósitos mais elevados da cultura sucumbem (MANCEBO et al., 2002, p. 327).

O controle minucioso das crianças se dá a partir do controle do meio, do tempo, do espaço, das atividades e do corpo. Nas Colônias de Férias, este tipo de controle é percebido facilmente (MATTOS et al., 2017; RANGEL; SILVA, 2017), porém, os professores entrevistados também relataram a influência da disciplina durante estes eventos. Esta característica assemelha as Colônias de Férias à Colônia de Gorki, onde jovens infratores possuíam uma rotina repleta de tarefas obrigatórias, inclusive àquelas voltadas ao lazer, e estavam sujeitos à punição caso alguma norma fosse descumprida (MAKARENKO, 2012).

Percebemos que, ao perguntarmos sobre a organização das crianças participantes, os professores alegaram que os princípios da Colônia eram contrários a qualquer desordem ou comportamento que se desvie do que é esperado pela instituição.

Não, eu acredito que acontece pelas características das crianças que vem. Pela Colônia não, até porque a gente prega os valores sociais o tempo inteiro de disciplina, cooperação, de superação (Entrevistado 2).

Aqui vemos que os profissionais estão preocupados em fazer da Colônia de Férias um ambiente organizado e controlado, onde eles são a autoridade 
perante as crianças. Eles possuem o poder e a responsabilidade de não deixarem as crianças saírem do que consideram comportamentos ideais para aquele ambiente. Percebemos também a relação da disciplina com os valores sociais. Ficou evidente, nos relatos dos professores, que a disciplina tem um peso importante nas Colônias de Férias.

O reconhecimento dos professores de que são autoridades na Colônia de Férias nos faz recorrer a Foucault (1993), quando afirma que o aparelho disciplinar capacita um olhar que vê tudo de maneira permanente. Assim, é ao mesmo tempo, uma fonte que ilumina tudo e lugar de convergência: nada foge deste olho e ele é o ponto para onde todos olham.

Segundo Silva (2012), os responsáveis pelas Colônias de Férias deveriam ser mediadores, o que na maioria dos casos não acontece. $O$ que ocorre é a reprodução de atividades em que o próprio responsável é o centro das atenções. Isso se dá devido a necessidade de atender as demandas vindas do mercado. Nas Colônias de Férias, o número de crianças é alto para que o lucro seja cada vez maior e a utilização de estratégias do poder disciplinar acaba sendo a maneira que os professores encontram para conseguirem desempenhar o trabalho diante da quantidade de crianças que são colocadas sob sua responsabilidade.

De acordo com o estudo de Saja (2013), estamos em uma sociedade de consumo e as práticas corporais estão servindo aos interesses do mercado. É por isso que as pessoas que trabalham na área da Educação Física devem ser sujeitos críticos e reflexivos em relação à essas práticas para que entendam como os praticantes atribuem significados e sentidos a elas.

A organização das Colônias de Férias é consequência da indústria do entretenimento e das práticas funcionalistas (SILVA, 2012). Deste fato provém o "pacote de atividades" que é imposto às crianças. Matos (2007) problematiza estas questões, destacando que o lazer é um tempo/espaço de liberdade e criação, entretanto, muitas vezes é produzido na esfera de circulação e do consumo. Isso acontece com o propósito de se alcançar principalmente o entretenimento e a ocupação do tempo livre, negando a espontaneidade dos sujeitos a partir dos planos padronizados.

Outro achado nessa pesquisa foi a violência.

[...] eu trabalhei na última Colônia com crianças de 3 a 5 anos, então você tem sempre que estar de olho neles. Se você virar 5 segundos pode ser que tenha uma criança batendo na outra (Entrevistado 8).

Isso chegou um caso de quase agressão, se a gente não intervém, ele ia brigar literalmente com um coleguinha a ponto de pegar um cabo de vassoura (Entrevistado 1). 
[...] vi muitas crianças brigando, seja por conta de lanche, seja por conta da atividade, ou porque uma se sentiu menosprezada pela outra, ou porque a outra chegou aqui e arrumou um amiguinho e uma amiga ficou com ciúmes e ai foi pra cima dessa criança. Ou ela também se sentiu menosprezada, enfim... Já vi também a criança querer bater em professor (Entrevistado 3).

A violência nas escolas já é investigada em diversos estudos, mas pouco analisada em Colônias de Férias. Giordani, Seffner e Dell'Aglio (2017) investigaram a percepção de estudantes e de professores acerca da violência no espaço escolar. A partir da análise de conteúdo, os autores estabeleceram categorias discursivas, incluindo a violência entre pares e a violência entre alunos e professores. Já Loureiro e Queiroz (2005) destacaram a violência na escola sob dois aspectos: o físico e o verbal. As causas da violência na escola foram relacionadas primeiramente à família desestruturada e ao ambiente em que o aluno ou a escola está inserido, o que indica uma visão pouco crítica das dinâmicas tecidas dentro da escola. Tal fato é semelhante em nossa pesquisa:

Violência é tudo o que prejudica o outro, agressão, pode ser verbal. Pode ser tudo que pode prejudicar o próximo. Existe a violência verbal e física. Considero a mais grave a física que gera um dano (Entrevistado 10).

Acho que todas são as mais graves, mas acredito que a fisica continue sendo a mais grave. Porque ela te atinge diretamente e pode causar danos irreversiveis também. Apesar da psicológica também ser muito grave, acredito que a fisica ainda deixa a sociedade mais espantada e chocada (Entrevistado 9).

Acho que a física foi a mais frequente, um beliscão, um tapa. Mas eu também vejo a verbal. As duas são graves. A física dói, mas as palavras podem ferir muito mais (Entrevistado 8 ).

As violências mais comuns que a gente também vê nas escolas que é mais de posse mesmo, como: Ah, isso é meu. E de preconceito, como: ah, você não vai brincar comigo porque você é assim ou assado. Eu acho que é o preconceito que atinge não só o físico, mas também o emocional. Às vezes, a criança carrega isso. É querer bater mesmo, é o ato de punir porque a criança quer alguma coisa (Entrevistado 7). 
Eu entendo por violência qualquer atitude que agrida o outro de forma fisica ou de forma emocional, psíquica, social, enfim [...] tem a violência fisica onde a gente tem o contato físico, agressão. No caso, a física eu acho que entra mais como algo consciente, entende? E os outros tipos de violência que entram na questão emocional, psíquica e social podem ser feitas de formas consciente ou inconsciente (Entrevistado 6).

Maranhão, et al. (2014) destacam que a violência sofrida pode ocorrer mais na forma de ameaças e humilhações. Em geral, são episódios contínuos no âmbito doméstico. Parece que a sociedade brasileira ainda conserva as marcas da sociedade colonial escravista, caracterizada pelo predomínio do espaço privado sobre o público, tendo como modelo de base a família patriarcal e com forte hierarquização. Maldonado e Williams (2005) coletaram dados com mães em visitas domiciliares. Os resultados apontam para correlações entre a violência escolar e condições socioeconômicas das famílias.

Marcel Soriano, Fernando Soriano e Evelia Jimenez (1994) afirmam que a violência escolar pode estar mais relacionada ao fato de crianças de diferentes culturas estarem juntas no mesmo ambiente. Essa hipótese parece estar mais convergente com a violência nas Colônias de Férias. Apesar das diversas experiências de violência se manifestarem nas Colônias de Férias, o lazer vivenciado ainda pode ser considerado uma forma de liberdade. Para isso, é preciso elaborar uma teoria crítica do lazer (HEMINGWAY, 1996). Nesse sentido, estudos que expõem como as práticas sociais regulam os corpos permitem, ao mesmo tempo, criar um espaço emancipatório (ROBINETT, 2014).

\section{Considerações finais}

Atualmente, é raro identificar alguma forma de lazer que tenha resistido à figura de mercadoria (MASCARENHAS, 2005). No presente estudo, encontramos indícios de insatisfação dos profissionais envolvidos devido à característica mercadológica impressa nas Colônias de Férias atuais. Esta insatisfação é produzida pela falta de qualidade do serviço que os profissionais reconhecem que estão realizando em decorrência do excesso de crianças que são colocadas em uma turma. Além disso, parece que a gestão das Colônias de Férias não considera a maneira que alguns professores gostariam de trabalhar.

É possível acreditar que essa insatisfação dos profissionais com o próprio trabalho vem da necessidade de atrelar uma atividade de lazer com a mecanização 
do trabalho. Essa necessidade surge quando eles precisam administrar grandes quantidades de alunos e as estratégias da disciplina, por exemplo, são utilizadas como forma de controle.

Estes são alguns pontos que podemos ressaltar como consequência da influência do pensamento de mercado nas Colônias de Férias na vida e trabalho de crianças e professores, respectivamente. Algumas crianças enxergam a Colônia de Férias como a escola, pois são apresentadas a uma série de atividades prontas para que a dinâmica e o andamento do evento sejam favoráveis ao lucro mediante as intenções dos gestores. Isso faz com que se caminhe de maneira contrária à chance de emancipação.

A lógica de mecanização do trabalho presente na escola, também se encontra na Colônia de Férias; a dimensão lúdica tem sido retirada de ambos os ambientes e o excesso de disciplina também é bastante visível. Na tentativa de conseguir um tempo para livrar-se da lógica de produção, o sujeito busca o lazer e acaba encontrando os mesmos traços desta lógica nele. Neste caso, a criança, depois de passar o ano inteiro frequentando a escola, encontra algumas características dela em um momento de lazer, que seria a Colônia de Férias.

O professor de Educação Física é antes de tudo um educador e sua atuação deve ir além da reprodução de movimentos e transmissão de conhecimento. É necessário que se entenda as questões relativas ao lazer e seu significado para o ser humano. Uma sugestão prática é a consideração da escolha e da escuta, possibilitando a democratização (SILVA, 2012). Além disso, as práticas de saúde e educação devem caminhar contra as condutas opressivas do mercado para que haja a produção de novas regras e ideias sob a perspectiva da justiça social através da mobilização das instituições (ARTUR, 2015).

Assim sendo, talvez as Colônias de Férias não possuam uma relação clara com o lazer, mesmo considerando a falta de consenso por parte da literatura que abarca esse conceito. A contribuição deste estudo para com aqueles que trabalham na área perpassa esta questão e envolve a sugestão de que é importante considerar todo contexto na qual as Colônias de Férias estão envolvidas. Isso inclui o "lazer" mercantilizado e todas as características disciplinares que as abraçam. Na tentativa de reduzir esta carga da sociedade industrial, produtivista e individualista em um momento importante para crianças e jovens, deve-se utilizar as ferramentas que permitam o questionamento e a escolha em pelo menos algumas atividades.

Em suma, podemos dizer que a mercantilização do lazer faz com que alguns profissionais precisem lançar mão de mecanismos comuns ao poder disciplinar. Isso porque o excesso de crianças por turma é uma escolha da gestão das Colônias de Férias para que haja cada vez mais lucro. Para controlar esse número grande de crianças, os professores lançam mão de técnicas do 
poder disciplinar. Essas técnicas envolvem manipulação calculada de gestos e comportamentos, controle de horários e atividades, valorização da hierarquia, da submissão e da obediência, entre outros, sempre com a intenção de manter a ordem e o equilíbrio.

Destarte, é possível que em uma Colônia de Férias o lazer, conforme descrito por Dumazedier (1979), não esteja inteiramente presente. Entretanto, é necessário apresentar e ensinar o que realmente é o lazer. Assim sendo, a produção de estudos que coloquem em foco as Colônias de Férias é indispensável, uma vez que, ainda que elas contenham características da escola, elas possuem objetivos, rotinas e dinâmicas diferentes ${ }^{3}$. Estudos considerando a opinião das crianças envolvidas é uma opção interessante para que se possa olhar este fenômeno por outro ângulo.

\section{REFERÊNCIAS}

ADORNO, Theodor; HORKHEIMER, Max. A indústria cultural: o iluminismo como mistificação das massas. In: LIMA, Luiz Costa. Teoria da cultura de massa. São Paulo: Paz e Terra, 1990.

ADORNO, Theodor; HORKHEIMER, Max. Dialética do esclarecimento: fragmentos filosóficos. 2. ed. Rio de Janeiro: Zahar, 1991.

AMADO, João. Manual de investigação qualitativa em educação. 3. ed. Imprensa da Universidade de Coimbra. Coimbra: University Press, 2017.

ANTUNES, Deborah C.; ZUIN, Antônio Álvaro S. Do bullying ao preconceito: os desafios da barbárie à educação. Psicologia \& Sociedade, Porto Alegre, v. 20, n. 1, p. 33-42, 2008.

ARTUR, Karen. Participação e direito à saúde dos trabalhadores. Saúde e Sociedade, São Paulo, v. 24, n. 3, p. 853-868, 2015.

BARDIN, Laurence. Análise de conteúdo. Lisboa: Edições 70, 2011.

BERTO, Rosianny C.; FERREIRA NETO, Amarilio; SCHNEIDER, Omar. Parques infantis e colônias de férias como espaços/tempos de educação da infância (1930-1940). Pensar a Prática, Goiânia, v. 12, n. 1, p. 1-12, 2009.

3 Ao pesquisarmos na Plataforma SciELO (dia 28/08/2019) por artigos científicos, publicados nos últimos 5 anos, que possuem no título as palavras "Colônia de Férias", nenhum estudo foi encontrado. 
BONDIA, Jorge Larrosa. Notas sobre a experiência e o saber de experiência. Rev. Bras. Educ., Rio de Janeiro, n. 19, p. 20-28, Apr. 2002.

BOURDIEU, Pierre. La distinction. Paris: Ed. de Minuit, 1979.

BOURDIEU, Pierre. La misère du monde. Paris: Ed. du Seuil, 1993.

BOURDIEU, Pierre. O campo político, o campo das ciências sociais e o campo jornalístico. In: BENSON, Rodney; NEVEU, Erik. Bourdieu e o campo jornalístico. Cambridge: Polity Press, 2005.

CAMARGO, Luiz Octávio de L. O que é lazer. São Paulo: Brasiliense, 2017.

CRUZ, Priscila A. S.; FREITAS, Silvane A. de. O poder disciplinar e a violência das instituições escolares: um estudo à luz de Michel Foucault e Áurea Guimarães. In: ENCONTRO DE INICIAÇÃO CIENTÍFICA, 9., n. 3, 2011, Dourados. Anais eletrônicos [...]. Dourados: Pró-Reitoria de Pesquisa e Pós-Graduação da Universidade Estadual de Mato Grosso do Sul, 2011. Disponível em: https://anaisonline.uems.br/index. php/enic/article/view/1547/0. Acesso em: jun. 2019.

DIKEN, Bulent; LAUSTSEN, Carsten. The Culture of Exception: Sociology Facing the Camp. London: Routledge, 2005.

DUMAZEDIER, Joffre. Sociologia empírica do lazer. São Paulo: Perspectiva: Ed. SESC, 1979.

FOUCAULT, Michel. Surveiller et punir. Paris: Éditions Gallimard, 1993.

FUCHS, Julien. Les colonies de vacances en France, 1944-1958: impulsions politiques autour d'un fait social majeur. Paedagogica Historica, [s. l.], v. 53, n. 5, p. 602-622, 2017.

FUGGLE, Sophie. Colonies de vacances. In: FUGGLE, Sophie; GLEDHILL, Nicolas (ed.). La ligned'écume: encountering the French beach. Strands book series. London: Pavement Books, 2016.

GIORDANI, Jaqueline P.; SEFFNER, Fernando; DELL'AGLIO, Debora D. Violência escolar: percepções de alunos e professores de uma escola pública. Psicologia Escolar e Educacional, São Paulo, v. 21, n. 1, p. 103-111, 2017.

HEMINGWAY, John. Emancipating leisure: The recovery of freedom in leisure. Journal of Leisure Research, [s.l.], v. 28, n. 1, p. 27-43, 1996.

HOUSSAYE, Jean. Le centre de vacances et de loisirs prisonnier de la forme scolaire. Revue Française de Pédagogie, [s.l.], n. 125, p. 95-107, 1998.

LEMA, Alejandra; RUIZ, Veronica; SCARLATO, Ines. Tiempo libre y espacio público: Marcas de una civilización. Educación Física Y Ciencia, [s.l.], v. 13, p. 51-62, 2011.

LOUREIRO, Ana Carla A. M.; QUEIROZ, Sávio S. de. A concepção de violência segundo atores do cotidiano de uma escola particular: uma análise psicológica. Psicologia: Ciência e Profissão, Brasília, v. 25, n. 4, p. 546-557, 2005. 
LUKÁCS, Georg. Histoire et conscience de classe: Essais de dialectique marxiste. Paris: Editions de Minuit, 1974.

MAKARENKO, Anton. Poema Pedagógico. 3 ed. São Paulo: Editora 34, 2012.

MALDONADO, Daniela P. A.; WILLIAMS, Lucia C. de A. O comportamento agressivo de crianças do sexo masculino na escola e sua relação com a violência doméstica. Psicologia em Estudo, Maringá, v. 10, n. 3, p. 353-362, 2005.

MANCEBO, Deise et al. Consumo e subjetividade: trajetórias teóricas. Estudos de Psicologia, Natal, v. 7, n. 2, p. 325-332, 2002.

MARANHÃO, Joyce H. et al. Violência, risco e proteção em estudantes de escola pública. Fractal: Revista de Psicologia, [s.l.], v. 26, n. 2, p. 429-444, 2014.

MARCELLINO, Nelson C. Estudos do lazer: uma introdução. 2. ed. Campinas: Autores Associados, 2000.

MARX, Karl. O Capital. Crítica da economia política. Livro 1. O processo de produção do capital. São Paulo: Boitempo, 2013.

MASCARENHAS, Fernando. Lazer e utopia: limites e possibilidades de ação política. Movimento, Porto Alegre, v. 11, n. 3, p.155-182, 2005.

MATOS, Amanda T. de A. Lazer e educação física: um estudo da construção e apropriação de saberes e práticas a partir da experiência esportiva na infância. Licere, Belo Horizonte, v. 10, n. 3, p. 1-35, 2007.

MARTÍNEZ, Pedro L. M. A educação do corpo fora da escola: as origens das colônias de férias na Espanha. Educar em Revista, Curitiba, n. 33, p. 23-37, 2009.

MENDES, Áquilas et al. A contribuição do pensamento da saúde coletiva à economia política da saúde. Saúde e Sociedade, São Paulo, v. 26, p. 841-860, 2017.

MUNNÉ, Frederic. Psicosociologia del tiempo libre: Un enfoque crítico. México, DF: Trilhas, 1980.

MATTOS, Rafael da S. et al. Colônias de Férias: disciplina e biopolítica infantil. Licere, Belo Horizonte, v. 20, n. 3, p. 392-423, 2017.

PADILHA, Valquíria. Tempo livre e capitalismo: um par imperfeito. São Paulo: Alínea, 2000.

PAULINO, Luciana F.; SIQUEIRA, Vera Helena F. de; FIGUEIREDO, Gustavo de O. Subjetivação do idoso em materiais de educação/comunicação em saúde: uma análise na perspectiva foucaultiana. Saúde e Sociedade, São Paulo, v. 26, p. 943-957, 2017.

RANGEL, Sonia O. C.; SILVA, Alessandra M. Em favor da infância e em caridade da Pátria: a criação da primeira colônia escolar de férias do Rio de Janeiro de 1923 a 1924. Revista Brasileira de História da Educação, Maringá, v. 17, n. 3, p. 121-151, 2017. 
REQUIXA, Renato. Sugestão de diretrizes para uma política nacional de lazer. São Paulo: Ed. Serviço Social do Comércio, Administração Regional no Estado de São Paulo, 1980. (Série Lazer, v. 2).

ROBINETT, Jeremy. Heteronormativity in Leisure Research: Emancipation as Social Justice. Leisure Sciences, [s.l.], v. 36, n. 4, p. 365-378, 2014.

SAJA, Juan Manuel. Políticas Públicas y Educación Física. Entrevista1 a Lino Castellani Filho. Educación Física Y Ciencia, Buenos Aires, v. 14, p. 75-81, 2013.

SANTOS, Paola L. P. dos. Mercantilização da saúde e cidadania perdida: o papel do sus na reafirmação da saúde como direito social. Revista da UNIFEBE, Brusque, v. 1, n. 11, p. 1-16, 2013.

SILVA, Débora A. M. Colônia de férias temática: fundamentando a ação a partir das contribuições de Paulo Freire. 2008. 104 f. Dissertação (Mestrado em Educação Física) Universidade Metodista de Piracicaba, Piracicaba, 2008.

SILVA, Débora A. M. Experiências com o lazer em colônias de férias temáticas. Campinas: Alinea, 2012.

SORIANO, Marcel; SORIANO, Fernando I.; JIMENEZ, Evelia. School violence among culturally diverse populations: Sociocultural and institutional considerations. School Psychology Review, [s.l.], v. 23, n. 2, p. 216-235, 1994.

VIANA, Nildo. A Mercantilização do lazer. Espaço Livre, [s.l.], v. 9, n. 18, p. 56-68, 2015.

Texto recebido em 28/08/2019.

Texto aprovado em 29/05/2020. 